\title{
Impact of initial antibiotic choice on mortality from pneumococcal pneumonia
}

\author{
J. Aspa*, O. Rajas*, F. Rodriguez de Castro\#, M.C. Huertas ${ }^{\Uparrow}$, L. Borderías ${ }^{+}$, \\ F.J. Cabello ${ }^{\S}$, J. Tábara ${ }^{\ddagger}$, S. Hernández-Flix**, A. Martinez-Sanchis ${ }^{\# \#}$ and A. Torres ${ }^{\star \uparrow}$, \\ on behalf of The Pneumococcal Pneumonia in Spain Study Group
}

\begin{abstract}
To determine the impact of initial antimicrobial choice on 30-day mortality rate in patients with community-acquired pneumonia due to Streptococcus pneumoniae (CAP-SP), a prospective, observational study was conducted in 35 Spanish hospitals. A total of 638 patients with CAP-SP were identified. Antimicrobials were chosen by the attending physician. Patients were grouped into the following categories: $\beta$-lactam monotherapy $(n=251)$, macrolide monotherapy $(n=37)$, $\beta$-lactam plus macrolide $(n=198)$, levofloxacin alone/combination $(n=48)$, and other combinations $(n=104)$. The reference category was $\beta$-lactam+macrolide.

The $\mathbf{3 0}$-day survival probability was $\mathbf{8 4 . 9 \%}$. Using multivariate survival analysis, factors related to mortality in the entire population were: bilateral disease, suspected aspiration, shock, HIV infection, renal failure and pneumonia severity index (PSI) score Class IV versus I-III and categories $\mathrm{V}$ versus I-III. The association of $\beta$-lactams+macrolides was not better than the use of $\beta$-lactams alone. The current authors analysed the different groups of patients with significant mortality/morbidity: intensive care unit, PSI Class >III, renal failure, chronic lung disease and bacteraemia. Only in patients with PSI Class $>$ III, who had undergone initial antimicrobial choice classified as other combinations, were associated with higher mortality.

In conclusion, the current authors have not demonstrated an independent association between initial antimicrobial regimen and 30-day mortality in community-acquired pneumococcal pneumonia patients, except for those with a higher pneumonia severity index score.
\end{abstract}

KEYWORDS: Antimicrobial resistance, mortality, pneumococcal pneumonia, risk factors, Streptococcus pneumoniae

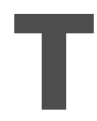
he effect of antimicrobial resistance and subsequent discordant antimicrobial therapy (DAT) on prognosis of communityacquired pneumonia due to Streptococcus pneumoniae (CAP-SP) has been evaluated in several studies, with conflicting results. Some studies have suggested that antibiotic resistance in $S$. pneumoniae is not clinically relevant [1-3], whereas others [4] have reported higher mortality rates among patients infected with nonsusceptible strains to the administered antibiotics. In a recent study by LUJAN et al. [4], it was observed that receiving DAT, as a result of an invasive infection with resistant S. pneumoniae isolates, resulted in a significantly higher chance of mortality. In contrast, $Y_{U}$ et al. [5], reported that DAT, amongst patients with bacteraemic pneumococcal disease who received monotherapy, was only associated with excess mortality when the isolate displayed high-level resistance to cefuroxime, but not with penicillins or cefotaxime.
Several retrospective studies have suggested that the use of a macrolides/ $\beta$-lactams combination, as part of the initial antimicrobial treatment, for patients with CAP, requiring hospital admission, may shorten the hospital stay $[6,7]$ and reduce the mortality rate in comparison with those treated with monotherapy [8-10], even when S. pneumoniae is finally identified as the causative organism [11-13]. However, many aspects of the apparently beneficial effects of combined therapy remain unclear and/or controversial. There are inconsistencies in reported outcomes and confusing biases that may have influenced these results. For instance, groups receiving the $\beta$-lactam/ macrolide combination, as opposed to monotherapy, are not comparable with regard to the average prognosis [10]. In a retrospective study on 213 hospitalised patients, BURGESS and LEWIS [14] concluded that it may not be necessary to add a macrolide to a nonpseudomonal thirdgeneration cephalosporin in the initial empirical
AFFILIATIONS

*Hospital de La Princesa, Madrid,

*Hospital Dr. Negrín, Gran Canaria,

'Hospital Juan Ramón Jiménez, Huelva,

${ }^{+}$Hospital San Jorge, Huesca,

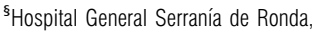
Málaga,

${ }^{f}$ Hospital Cristal Piñor, Orense,

**Hospital Sant Joan. Reus, Tarragona,

\#\#Hospital Marina Baixa, Villajoyosa,

Alicante, and

๑Hospital Clínic Barcelona, Spain.

\section{CORRESPONDENCE}

J. Aspa, Rajas, Servicio de Neumología Hospital Universitario de La Princesa,

C/ Diego de León, 62, 28006, Madrid, Spain.

Fax: 34915202487

E-mail: jaspa@separ.es

Received

November 022004

Accepted after revision:

January 182006

SUPPORT STATEMENT

This study was designed by an ad hoc Scientific Committee created by the

Sociedad Española de Neumologia y Cirugía Torácica (SEPAR) through its Área de Tuberculosis e Infecciones Respiratorias (TIR). An independent firm (Pharma Consult Madrid) was engaged to carry out the administrative management, the cost of which was paid by AVENTIS. Expenses arising from the study on antibiotic sensitivity of pneumococcal strains and their serotypes, performed in the "Centro Nacional de Microbiología" (Majadahonda, Madrid), were supported by a grant from the Fundación RESPIRA, Fundación Española del Pulmón. Data analysis was carried out by the signatory authors of this manuscript with support of the Red-Respira (RTIC C03/11).

European Respiratory Journa Print ISSN 0903-1936

Online ISSN 1399-3003 
therapy of CAP. Furthermore, JOHANSEN et al. [15] reported that the combination of penicillin-erythromycin is antagonistic to $S$. pneumoniae both in vitro and in animal models of invasive disease, suggesting that $\beta$-lactam antibiotics and macrolides should not be administered together, unless pneumococcal infection is ruled out. Data from a recent, prospective multicentre study of patients with bacteraemic pneumococcal illness [16], suggests that combination antibiotic therapy improves survival but only among critically ill patients, and without being able to demonstrate any advantage of regimens including macrolides in comparison with nonmacrolide combinations.

In Spain, almost $40 \%$ of pneumococci strains express diminished susceptibilty to penicillin and approximately one-third of the isolates are macrolide resistant, most of them having macrolides lincosamides streptogramin-B phenotype [17]. The current authors, therefore, considered that Spain provides a good environment in which to respond to the previously mentioned controversies. Consequently, an observational, multicentre study, on a large series of patients with pneumococcal pneumonia was conducted in Spain to determine the impact of initial antimicrobial therapy and its effect on mortality.

\section{MATERIAL AND METHODS Patients and study design}

From January, 1999 to April, 2000, 638 consecutive adults with CAP-SP were enrolled in 35 Spanish hospitals [17]. A 30-day mortality, from the time of diagnosis, was considered the endpoint of the analysis [18]. Those patients whose 30-day mortality could not be verified $(n=66)$, mainly because they were transferred to other centres, were also included in the analysis with data censored at the date of transfer. Figure 1 shows the Kaplan-Meier plots of patients included in the study.

\section{Diagnostic criteria}

CAP was assumed in the presence of acute onset of signs and symptoms, suggesting lower respiratory tract infection and radiographical evidence of a new pulmonary infiltrate that had no other known cause. Microbial investigation techniques, administration of antimicrobial agents and other therapies was left to the discretion of the attending physician. Investigators of every collaborative institution prospectively collected all data

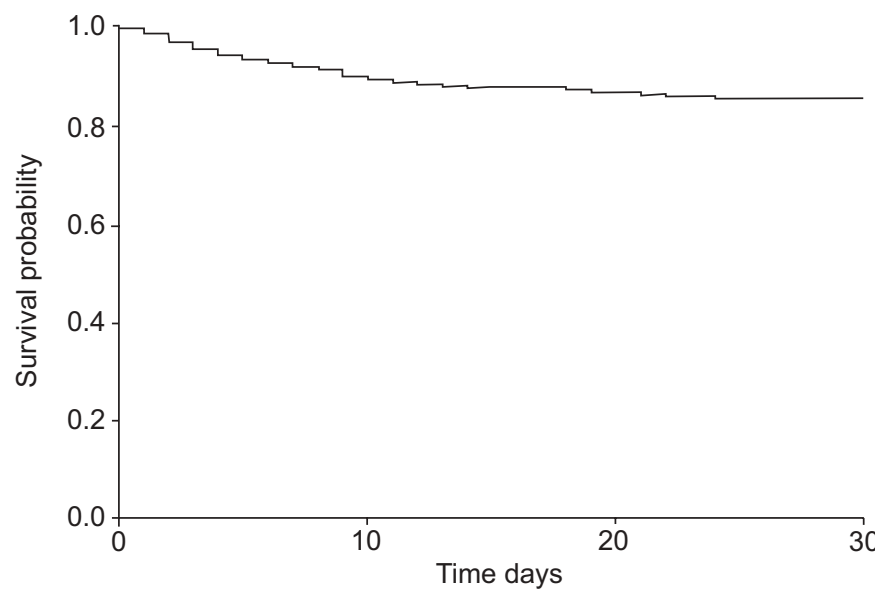

FIGURE 1. Survival analysis. Kaplan-Meier plots of patients included in the study $(n=638)$

according to a standardised protocol. A diagnosis of probable CAP-SP was made in cases where there was a predominance of Gram-positive cocci in pairs and chains, and heavy growth of S. pneumoniae in validated sputum and/or tracheobronchial aspirates. A definite diagnosis of pneumococcal pneumonia was considered with one of the following criteria. 1) At least one blood, pleural fluid, or transthoracic needle aspiration culture positive for S. pneumoniae. 2) Bacterial growth of $\geqslant 10^{3}$ colony-forming units $(\mathrm{cfu}) \cdot \mathrm{mL}^{-1}$ of $S$. pneumoniae from a protected specimen brush and/or $\geqslant 10^{4} \mathrm{cfu} \cdot \mathrm{mL}^{-1}$ in bronchoalveolar lavage. 3) Positive urinary antigen for S. pneumoniae with a diagnosis of probable pneumococcal pneumonia. The yields of microbial investigations are shown in table 1 .

\section{In vitro susceptibility testing and serotyping}

Pneumococcal isolates from every patient were available for examination. All pneumococcal isolates were submitted to the National Center of Microbiology for serotyping [17, 19, 20] and susceptibility verification, according to the National Committee for Clinical Laboratory Standards 2002 [21]. The following antibiotics were tested: penicillin, amoxicillin, cefuroxime, cefotaxime, imipenem, vancomycin, teicoplanin, erythromycin, tetracycline, chloramphenicol and levofloxacin. Clarithromycin and azithromycin were considered the same as erythromycin in terms of susceptibility and resistance. Ceftriaxone and cefotaxime were also considered equivalent.

\section{Antibiotic therapy}

Initial antimicrobial therapy was defined as all antimicrobial agents used at the instance CAP was diagnosed and administered consistently after the first dose until the microbiological results were available. To be eligible for analysis, the daily dose of an antibiotic should have been the minimum dose recommended for treatment of a systemic infection [22].

Patients were divided into cohorts, based on the initial antibiotic regimen. The following all-exclusive antimicrobial

\section{TABLE 1 Diagnostic procedures used in pneumococcal pneumonia}

Diagnostic procedure

Sputum

Bronchial aspirate

Blood culture

Pleural fluid culture

Protected brush catheter

BAL

Transthoracic punction

Open lung biopsy

Autopsy

Pneumococcal urinary antigen

Legionella spp. urinary antigen

Mycoplasma spp. IgM
Procedures undertaken Positive finding

$\begin{array}{cc}316(49.5) & 181(28.4) \\ 108(16.9) & 70(11) \\ 583(91.4) & 427(67) \\ 79(12.4) & 32(5) \\ 20(3.1) & 14(2.2) \\ 19(3) & 8(1.3) \\ 2(0.3) & 2(0.3) \\ 2(0.3) & \\ 68(10.7) & 17(2.7) \\ 160(25.1) & 1(0.2) \\ 109(17.1) & \end{array}$

All data are presented as $n$ (\%). A definite diagnosis of pneumococcal community-acquired pneumonia was achieved in $73 \%$ of procedures and a diagnosis of probable pneumococcal pneumonia was recorded in the remaining 27\%. BAL: bronchoalveolar lavage; IgM: immunoglobulin M. 
TABLE 2 Univariate analysis relative to 30-day mortality

\begin{tabular}{|c|c|c|c|c|c|}
\hline Variables & Cases n & $\%(95 \% \mathrm{Cl})$ & HR (95\% CI ) & \multicolumn{2}{|c|}{ p-value ${ }^{\#}$} \\
\hline \multicolumn{6}{|l|}{ Antibiotics } \\
\hline \multicolumn{6}{|l|}{ Macrolides+ } \\
\hline Second GCS & 16 & & & & \\
\hline Third GCS & 156 & & & & \\
\hline Imipenem & 3 & & & & \\
\hline Others & 2 & & & & \\
\hline$\beta$-Lactams & 251 & $39.3(35.6-43.1)$ & $0.66(0.39-1.10)$ & 0.114 & \\
\hline Second GCS & 25 & & & & \\
\hline Third GCS & 86 & & & & \\
\hline Others & 42 & & & & \\
\hline Macrolides & 37 & $5.8(4.1-7.9)$ & $0.15(0.02-1.13)$ & 0.065 & \\
\hline Levofloxacine & 48 & $7.5(5.6-9.8)$ & $0.24(0.06-1.03)$ & 0.054 & \\
\hline Alone & 38 & & & & \\
\hline Combination $^{+}$ & 10 & & & & \\
\hline Other combinations & 104 & $16.3(13.4-19.2)$ & $2.16(1.31-3.55)$ & 0.002 & $<0.001$ \\
\hline Second/third/fourth GCS+ aminoglycoside & 16 & & & & \\
\hline Any $\beta$-lactam+macrolide+aminoglycoside & 6 & & & & \\
\hline Aminoglycosides & 11 & & & & \\
\hline \multicolumn{6}{|l|}{ Antibiotic combinations including } \\
\hline Vancomycin & 5 & & & & \\
\hline IV & 234 & $36.7(32.9-40.4)$ & $3.77(1.86-7.68)$ & $<0.001$ & \\
\hline V & 147 & $23.0(19.8-26.3)$ & $10.36(5.25-20.43)$ & $<0.001$ & $<0.001$ \\
\hline ICU admission & 125 & $19.6(16.5-22.7)$ & $3.52(2.33-5.31)$ & & $<0.001$ \\
\hline Shock $\# \#$ & 102 & $16.0(13.1-18.8)$ & $13.56(8.81-20.87)$ & & $<0.001$ \\
\hline Tobacco" & 377 & $59.1(55.3-62.9)$ & $0.67(0.45-1.01)$ & & 0.056 \\
\hline Chronic pulmonary disease $^{++}$ & 254 & $39.8(36.0-43.6)$ & $0.59(0.38-0.93)$ & & 0.023 \\
\hline HIV infection ${ }^{\S \S}$ & 61 & $9.6(7.4-12.1)$ & $1.70(0.95-3.06)$ & & 0.076 \\
\hline Polymicrobial pneumonia ${ }^{f f}$ & 34 & $5.3(3.7-7.8)$ & $1.74(0.84-3.59)$ & & 0.135 \\
\hline \multicolumn{6}{|l|}{ Adequacy of treatment ${ }^{\# \# \#}$} \\
\hline Concordant & 560 & $87.8(85.2-90.3)$ & 1 & & \\
\hline Discordant type 1 & 37 & $5.8(4.1-7.9)$ & $1.35(0.62-2.93)$ & 0.448 & \\
\hline Discordant type 2 & 41 & $6.4(4.6-8.6)$ & $1.70(0.85-3.39)$ & 0.134 & 0.268 \\
\hline \multicolumn{6}{|l|}{ Penicillin susceptibility } \\
\hline Sensitive & 409 & $64.1(60.4-67.8)$ & 1 & & \\
\hline Intermediate & 164 & $25.7(22.3-29.1)$ & $1.46(0.93-2.30)$ & 0.100 & \\
\hline Resistant & 65 & $10.2(7.8-12.5)$ & $1.55(0.82-2.91)$ & 0.175 & 0.165 \\
\hline Typical symptomatology & 106 & $16.6(13.7-19.5)$ & 2.09 (1.32-3.32) & & 0.002 \\
\hline Renal failure ${ }^{+++}$ & 127 & $19.9(16.8-23)$ & $5.06(3.36-7.62)$ & & $<0.001$ \\
\hline Bacteraemia & 429 & $67.2(63.6-70.9)$ & $1.03(0.67-1.59)$ & & 0.898 \\
\hline
\end{tabular}




\begin{tabular}{|c|c|c|c|c|c|}
\hline Variables & Cases n & $\%(95 \% \mathrm{Cl})$ & HR (95\% CI ) & \multicolumn{2}{|c|}{ p-value ${ }^{\#}$} \\
\hline \multicolumn{6}{|l|}{ Serotype } \\
\hline$B^{f f f}$ & 428 & $67.1(63.4-70.7)$ & $90330(0)$ & 0.846 & \\
\hline $\mathrm{C}^{\# \# \# \#}$ & 68 & $10.7(8.3-13.1)$ & $159235(0)$ & 0.838 & 0.087 \\
\hline
\end{tabular}

agent categories were established: $\beta$-lactam monotherapy $(n=251)$, macrolide monotherapy $(n=37), \beta$-lactam + macrolide $(n=198)$, levofloxacin alone $(n=38)$ or in combination $(n=10)$, and other combinations $(n=104)$. The reference category therapy was $\beta$-lactam+macrolide, as it is one of the most broadly accepted and commonly used options for patients with moderate-to-severe CAP. Days on antibiotics (oral/i.v.) were also evaluated. Antibiotic treatment was considered concordant if at least one antibiotic administered during the first $48 \mathrm{~h}$, after the specimen was obtained for culture, showed full in vitro sensitivity (neither intermediate nor resistance) against the isolated strains. Therapies without this criterion were defined as discordant and classified as: Type 1, when pneumococcal strains showed intermediate susceptibility to the administered therapy; or Type 2, when the infection was caused by pneumococcal strains resistant to the administered regimen.

\section{Statistical analysis}

For the primary end-point, a cumulative 30-day mortality was used (dependent variable). The independent variables were chosen as those found previously, according to the literature, to be associated with mortality (table 2). Categorical variables were compared using the Fisher's exact and the Chi-squared tests, with Yates' correction when necessary. Survival curves were constructed according to the methods of Kaplan and Meier, and comparisons of the survival curves were performed with a two-sided log-rank test. Multivariate analyses were performed with the use of a Cox proportional-hazards regression model to identify variables that were independently predictive of outcome [24]. Those variables showing an association with survival in the univariate analysis with significance level of $\mathrm{p}<0.2$ were included in the Cox model. Data were analysed using computer software. Institutional review board approval was obtained according to local requirements.

\section{RESULTS \\ Patient characteristics}

The study population was composed of 638 patients. The mean (range) patient age was 61.58 yrs (18-97) and 64.7\% were male. The variables included in the analysis are presented in table 2.

\section{Diagnosis of pneumococcal pneumonia}

Of the S. pneumoniae isolates, 427 out of the $638(67 \%)$ patients were recovered from blood samples (table 1). Serological samples were taken from $340(53.3 \%)$ patients on admission and 204 (32\%) during convalescence. Overall, 195 (30.6\%) patients had paired samples. Mixed infections were present in $34(5.4 \%)$ patients. The most important were: influenza A/B virus $(\mathrm{n}=14)$, Escherichia coli $(\mathrm{n}=4)$, coagulase-positive staphylococci $(\mathrm{n}=4)$, Haemophilus influenzae $(\mathrm{n}=3)$, Legionella spp. $(\mathrm{n}=3)$, and Chlamydophila pneumoniae $(\mathrm{n}=3)$. Overall, six patients presented infections with three organisms, and 24 with two organisms. All mixed infections were adequately treated, except for those cases in which viruses were involved.

\section{Microbiological pattern}

The proportion of pneumococcal isolates with diminished susceptibility to antibiotics was: penicillin $35.7 \%$ (10.2\% highlevel resistance), cefuroxime $32 \%$, cefotaxime $2.8 \%$, imipenem $26.3 \%$, levofloxacin $0.6 \%$ and $27.4 \%$ showed a minimum inhibitory concentration (MIC) to erythromycin of $128 \mu \mathrm{g} \cdot \mathrm{mL}^{-1}$ [17].

\section{Initial antimicrobial therapy}

Overall, 59 specific antimicrobial regimens were prescribed in this series. Amoxicillin/clavulanate was the most commonly 


\begin{tabular}{|c|c|c|c|c|c|c|}
\hline \multirow{2}{*}{$\begin{array}{l}\text { Empirical } \\
\text { therapeutic option }\end{array}$} & \multirow{2}{*}{$\begin{array}{l}\text { Patients } \\
\text { n (\%) }\end{array}$} & \multirow{2}{*}{$\begin{array}{l}\text { Concordant } \\
\text { treatment }^{\#}\end{array}$} & \multicolumn{2}{|c|}{ PSI score I-III } & \multicolumn{2}{|c|}{ PSI score IV, V } \\
\hline & & & Patients & 30-day mortality & Patients & 30-day mortality ${ }^{+}$ \\
\hline$\beta$-Lactams+macrolides & $198(31)$ & $94.4(90.3-97.2)$ & $72(36.4,29.7-43.5)$ & $6(8.3,3.1-17.3)$ & $126(63.6,56.5-70.3)$ & $25(19.8,13.3-27.9)$ \\
\hline Macrolides & $37(5.8)$ & $64.9(47.5-79.8)$ & $24(64.9,47.5-79.8)$ & $1(4.2,0.1-21.1)$ & $13(35.1,20.2-52.5)$ & 0 \\
\hline $\begin{array}{l}\text { Levofloxacin } \\
\text { (mono/polytherapy) }\end{array}$ & $48(7.5)$ & $100(92.6-100)$ & $22(45.8,31.4-60.8)$ & 0 & $26(54.2,39.2-68.6)$ & $2(7.7,0.9-25.1)$ \\
\hline \multirow[t]{2}{*}{ Other combinations } & $104(16.3)$ & $80.8(71.9-87.8)$ & $30(28.8,20.4-38.6)$ & $1(3.3,0.1-17.2)$ & $74(71.2,61.4-79.6)$ & $30(40.5,29.3-52.6)$ \\
\hline & $638(100)$ & $87.8(85.2-90.3)$ & $257(40.3,36.5-44.1)$ & $10(3.9,1.8-7)$ & $381(59.7,55.9-63.5)$ & $82(21.5,17.4-25.6)$ \\
\hline
\end{tabular}

Data are presented as $n(\%), n(95 \%$ confidence intervals $(\%))$ or $n(\%, 95 \% \mathrm{Cl})$. Antibiotic treatment was considered concordant if at least one antibiotic administered during the first $48 \mathrm{~h}$ after the specimen was obtained for culture showed full in vitro sensitivity (neither intermediate nor resistant) against the isolated strains. ${ }^{*}: \mathrm{p}<0.0001$; : $p=0.203 ;{ }^{+}: p=0.001$.

used monotherapy regimen $(n=106,16.6 \%$ patients $)$ and therapy with a third-generation cephalosporin+macrolide was the most frequent combination with 156 regimens (24.5\%). The initial antimicrobial choice according to baseline severity of illness, as measured by pneumonia severity index (PSI) [23] and mortality, is summarised in table 3. Almost twothirds $(63.6 \%)$ of $\beta$-lactam+macrolide combinations were prescribed for patients with PSI Class IV-V, whereas $64.9 \%$ of macrolide-monotherapy regimens were prescribed for patients with PSI Class I-III. As a result of the high levels of resistance to macrolides in this series, DAT was more frequently found among patients receiving these antimicrobials $(\mathrm{p}<0.0001$, table 3$)$. There were subsequent changes in the antimicrobial regimen in 107 patients. In all of these patients, the initial therapy was modified $48 \mathrm{~h}$ after beginning the treatment. Changes in the initial antibiotic selection were not significantly associated with a 30-day mortality.

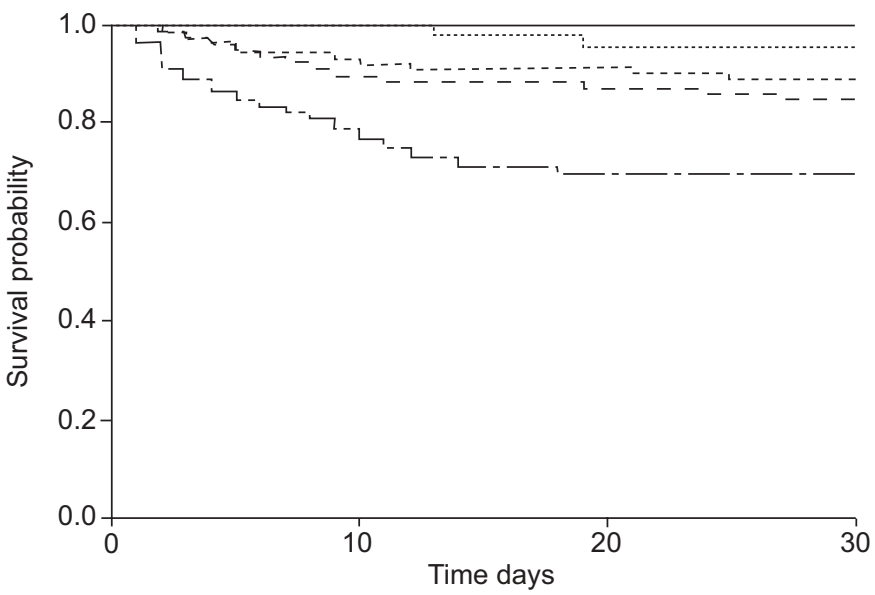

FIGURE 2. Survival analysis. Kaplan-Meier plots according to different antibiotic regimens ( $n=638$ patients). —_: macrolide; …......: levofloxacin; - - - -: $\beta$-lactam; - - - -: $\beta$-lactam+macrolide; - - - - -: other combinations.

\section{Mortality and empirical antimicrobial selection for the entire population}

The 30-day survival probability of the current cohort was $84.9 \%$ (95\% CI 82-7). The mean follow-up of patients who died was 10.3 days (median 8.5$)$. A total of $78(12.1 \%)$ patients received DAT (type 1 or 2 ) and $16(20.5 \%)$ died. This variable was not associated with an increase in mortality in the univariate analysis (table 2). Survival analysis by antibiotic therapy groups (Kaplan-Meier plots) is shown in figure 2. The multivariate analysis of factors related to mortality is shown in table 4 . Neither resistance to penicillin nor the initial empirical

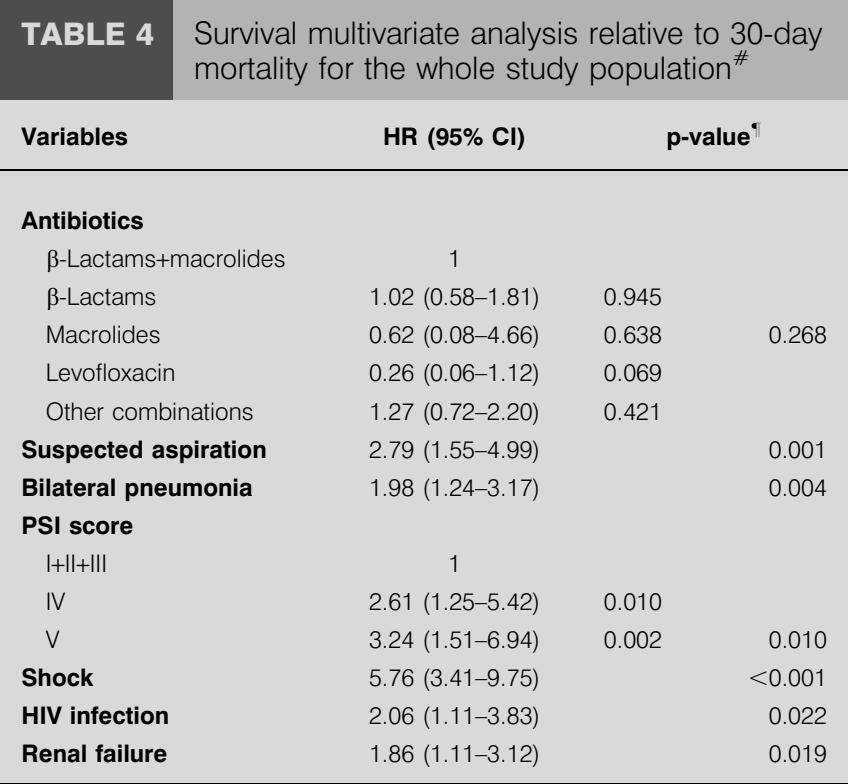

HR: hazard ratio; PSI: pneumonia severity index. For the full definition of each variable refer to table $2 .{ }^{*}: \mathrm{n}=638$ patients; " : for those variables with several categories the first column of $\mathrm{p}$-values compares every category of the variable to the reference category. The second column shows the significance of the variable as a whole. HR p-values were calculated using Cox regression models; for further explanations see Methods section. 
antimicrobial regimen or its concordance, were significantly related to mortality. Although the empirical antimicrobial choice was associated with mortality on univariate analysis, statistical significance disappeared upon the multivariate analysis. Using the $\beta$-lactam+macrolide combination as the reference category for initial antimicrobial therapy, only macrolides and levofloxacin showed hazard ratio (HR) $<1$. An encouraging trend in the multivariate analysis stands out in reference to mortality when levofloxacin is used, although the sample size is small (48 patients) and is not statistically significant (table 4).

In order to make the class of $\beta$-lactams more homogeneous, the current authors performed a restricted analysis on patients treated with amoxicillin/clavulanate or non-pseudomonal third-generation cephalosporin, alone or in combination with a macrolide. Mortality for monotherapy/combination was 10.8 and $15.1 \%$ (Fisher's exact test 0.237 ), respectively. Some authors $[7,8,11]$ have suggested that penicillins are inferior to cephalosporin monotherapy or as the $\beta$-lactam component of combination therapy. However, the present authors did not observe any significant difference when patients receiving amoxicillin monotherapy were compared with those receiving cephalosporin monotherapy (Fisher's exact test 0.538 ).

The following factors were significantly associated with mortality when survival analysis (Cox regression model) was applied: bilateral disease (HR 1.98, 95\% CI 1.24-3.17, $\mathrm{p}=0.004$ ), aspiration $(2.79,1.55-4.99, \mathrm{p}=0.001)$, shock $(5.76,3.41-9.75$, $\mathrm{p}<0.0001$ ), HIV infection (2.06, 1.11-3.83, $\mathrm{p}=0.022$ ), renal failure $(1.86,1.11-3.12, p=0.019)$ and PSI score categories I-III versus IV $(2.61,1.25-5.42, \mathrm{p}=0.010)$ and categories I-III versus $\mathrm{V}$ $(3.24,1.51-6.94, p=0.002$; table 4$)$. Regarding initial antimicrobial choices or mortality rates, the current authors have not found significant differences among hospitals in the current series.

\section{Mortality and empirical antimicrobial selection for selected groups of patients}

For the purpose of clinical interest, and because it has been assessed in several previous publications, factors related to mortality were analysed using the same protocol as that for the entire population. This was performed on the following groups of patients. 1) Patients admitted to the intensive care unit (ICU), mortality $32.8 \%$. 2) Patients with PSI Class >III, mortality $21.5 \%$. 3) Patients who developed renal failure during the current episode, mortality $37.8 \%$. 4) Patients with chronic lung disease, mortality $10.6 \%$. 5) Patients who contracted bacteraemia, mortality $14.5 \%$ (table 5).

Three points should be noted here. First, in patients with PSI Class >III $(n=381)$, the initial antimicrobial choice referred to as other combinations, presented a statistically significant association with mortality (HR 2, 95\% CI 1.2-3.4, $\mathrm{p}=0.013$ ). Secondly, when the current authors considered the antimicrobial choice as an overall variable in this group of patients, the $p$-value was also significant ( $p=0.039$, table 5$)$. Thirdly, in those patients who developed renal failure during the episode, penicillin susceptibility is significantly related to mortality (table 5).

\section{DISCUSSION}

In the current study the authors have assessed the relationship between empirical antibiotic treatment and mortality in
TABLE 5 Survival multivariate analysis in selected groups

\begin{tabular}{|c|c|c|c|}
\hline \multirow{2}{*}{$\begin{array}{l}\text { Variables } \\
\text { ICU }\end{array}$} & \multirow[t]{2}{*}{ HR $(95 \% \mathrm{Cl})$} & \multicolumn{2}{|c|}{ p-value ${ }^{\#}$} \\
\hline & & & \\
\hline Antibiotics & & & \\
\hline$\beta$-Lactams+macrolides & 1 & & \\
\hline$\beta$-Lactams & $0.45(0.18-1.22)$ & 0.116 & \\
\hline Macrolides & 0 & 0.984 & \\
\hline Levofloxacin & $0.73(0.1-5.6)$ & 0.762 & 0.082 \\
\hline Other combinations & $1.84(0.9-3.6)$ & 0.074 & \\
\hline Shock & $3.7(1.5-8.8)$ & & 0.004 \\
\hline Renal failure & $3.2(1.5-7)$ & & 0.003 \\
\hline Typical symptoms & $2.3(1.1-5.2)$ & & 0.038 \\
\hline \multicolumn{4}{|l|}{$\begin{array}{l}\text { PSI Class }>\text { III } \\
\text { Antibiotics }\end{array}$} \\
\hline$\beta$-Lactams+macrolides & 1 & 0.187 & \\
\hline$\beta$-Lactams & $1.49(0.8-2.7)$ & 0.967 & 0.039 \\
\hline Macrolides & 0 & 0.162 & \\
\hline Levofloxacin & $0.36(0.08-1.5)$ & 0.013 & \\
\hline Other combinations & $2(1.2-3.4)$ & & \\
\hline Bilateral pneumonia & $2.28(1.4-3.7)$ & & 0.001 \\
\hline Shock & $6.5(4.1-10.3)$ & & $<0.001$ \\
\hline HIV infection & $2.24(1.2-4.2)$ & & 0.014 \\
\hline \multicolumn{4}{|l|}{$\begin{array}{l}\text { Renal failure } \\
\text { Antibiotics }^{\S}\end{array}$} \\
\hline$\beta$-Lactams+macrolides & 1 & & \\
\hline$\beta$-Lactams & $0.51(0.2-1.2)$ & 0.136 & \\
\hline Macrolides & $1.9(0.2-14.8)$ & 0.537 & \\
\hline Levofloxacin & $0.3(0.04-2.4)$ & 0.245 & 0.094 \\
\hline Other combinations & $1.5(0.8-2.9)$ & 0.249 & \\
\hline Bilateral pneumonia & $2.3(1.2-4.5)$ & & 0.015 \\
\hline Shock & $6(2.7-13.1)$ & & $<0.001$ \\
\hline $\begin{array}{l}\text { Penicillin susceptibility } \\
\text { Sensitive }\end{array}$ & 1 & & \\
\hline Intermediate & $2.9(1.4-6)$ & 0.004 & \\
\hline Resistant & $2.9(1.2-7.3)$ & 0.023 & 0.006 \\
\hline Typical symptoms & $2.7(1.2-6.1)$ & & 0.014 \\
\hline \multicolumn{4}{|l|}{$\begin{array}{l}\text { Chronic lung disease } \\
\text { Antibiotics }\end{array}$} \\
\hline$\beta$-Lactams+macrolides & 1 & & \\
\hline$\beta$-Lactams & $0.6(0.3-1.5)$ & 0.323 & \\
\hline Macrolides & 0 & 0.986 & \\
\hline Levofloxacin & 0 & 0.961 & 0.771 \\
\hline Other combinations & $1.2(0.5-3.2)$ & 0.711 & \\
\hline Shock & $7.6(3.5-16.3)$ & & $<0.001$ \\
\hline \multicolumn{4}{|l|}{$\begin{array}{l}\text { Bacteraemia }^{\# \#} \\
\text { Antibiotics }^{-}\end{array}$} \\
\hline$\beta$-Lactams+macrolides & 1 & & \\
\hline$\beta$-Lactams & $1.2(0.6-2.4)$ & 0.576 & \\
\hline Macrolides & $0.8(0.1-6.5)$ & 0.867 & \\
\hline Levofloxacin & $0.3(0.04-2.5)$ & 0.275 & 0.226 \\
\hline Other combinations & $1.8(1-3.4)$ & 0.053 & \\
\hline Bilateral pneumonia & $2.2(1.3-3.9)$ & & 0.005 \\
\hline $\begin{array}{c}\text { PSI score } \\
1+11++11\end{array}$ & 1 & & \\
\hline IV & $3.4(1.3-8.6)$ & 0.010 & \\
\hline v & $5.6(2.3-13.8)$ & $<0.001$ & 0.001 \\
\hline Shock & $7.7(4.3-13.9)$ & & $<0.001$ \\
\hline Typical symptoms & $2.4(1.3-4.3)$ & & 0.004 \\
\hline
\end{tabular}

HR: hazard ratio; 95\% Cl: 95\% confidence interval; PSI: pneumonia severity index. For the full definition of each variable refer to table $2 .{ }^{*}$ : For those variables with several categories the first column of p-values compares every category of the variable to the reference category. The second column shows the significance of the variable as a whole. ${ }^{\circ}: n=125 ;^{+}: n=381 ;$ s: $n=127 ;{ }^{f}: n=254{ }^{\# \#}: n=429 ;$ HR $p$-values were calculated by Cox regression models; for further explanations see Methods section. 
CAP-SP patients following two different strategies: 1) the analysis of the population as a whole, and 2) the analysis of those groups of patients of particular interest, due to their mortality/morbidity.

When the entire population was evaluated, the most important finding was that neither the initially prescribed antimicrobial regimen nor its concordance was independently associated with mortality. Likewise, the association of $\beta$-lactams+macrolides is not better than the use of $\beta$-lactams alone in these patients. This finding would support the theory that treatment of CAP could be scaled down to monotherapy, once the pneumococcal aetiology had been ascertained, at least in patients with moderately severe disease. An encouraging nonsignificant trend stands out in reference to mortality when levofloxacin is used. Interestingly, in a randomised trial, FINCH et al. [25] found that patients treated with moxifloxacin had lower mortality and a shorter length of stay in hospital than those treated with a $\beta$-lactam, with or without a macrolide. It has also been recently reported that initial treatment with fluoroquinolones (levofloxacin $89.5 \%$ ) is independently associated with a lower risk of treatment failure [26].

The current authors have also evaluated some clinically relevant situations (table 5), mainly in ICU patients and those with renal failure, chronic lung disease, bacteraemic pneumonia or PSI Class >III. In this latter case, the initial antimicrobial choice was associated with mortality. This means that in patients with PSI Class $>$ III the choice of an antimicrobial regimen, other than $\beta$-lactam monotherapy, macrolide monotherapy, $\beta$-lactam+macrolide or levofloxacin alone or in combination, was associated with higher mortality. It is also remarkable that in bacteraemic patients, the choice of other combinations is close to the statistical significance regarding a major risk of mortality (HR 1.8, 95\% CI 1-3.4, $\mathrm{p}=0.053$; table 5). Finally, a subset analysis showed similar outcomes in patients with penicillin-susceptible $S$. pneumoniae versus those with penicillin-resistant isolates, except for the subgroup of patients with renal failure, in whom reduced susceptibility to penicillin was independently related to an increase in mortality (table 5). This is probably due to the more frequent use of antibiotics in these patients.

The lack of unique clinical features that accurately identify the specific pathogen, the increased antibiotic resistance, an unknown number of mixed infections and the great number of antibiotic choices, are some of the reasons that surround the debate. GLEASON et al. [8], showed that in almost 13,000 elderly in-patients with CAP, the initial therapy with a secondgeneration cephalosporin+macrolide, a nonpseudomonal third-generation cephalosporin+macrolide, or a fluoroquinolone alone, was independently associated with a lower 30-day mortality in patients hospitalised with pneumonia, than was therapy with a nonpseudomonal third-generation cephalosporin. The implications from these findings are that routine therapy against atypical pathogens may be important, even in elderly patients with CAP. In another population-based retrospective study [9], the inclusion of macrolides or fluoroquinolones in the initial empirical CAP therapy was also associated with improved survival, but this association varied from year to year, probably as a result of a temporal variation in the incidence of atypical pathogen. BROWN et al. [7] recently published another analysis of younger patients with CAP in which they demonstrated that the combination of ceftriaxone+macrolide was superior to other regimens, with respect to mean length of hospital stay and in-hospital mortality. However, this study raises the same questions as previous retrospective studies. For example, no information concerning the adequacy of diagnosis and therapy exists and only limited information regarding pathogens was available. Additionally, the authors did not assess the most sickpatient population, with severity of illness as one of the main factors that helps to select an initial antibiotic regimen. It is, therefore, interesting to note that a recently published, retrospective study, by WATERER et al. [11], which, with a design similar to the present study, concludes that adults with severe bacteraemic nonresistant CAP-SP have a significantly higher risk of death if they receive a single antibiotic rather than a combination of effective therapy. This supports the findings of other studies [12, 13], which found that dual antimicrobial therapy, including a macrolide, reduced mortality associated with bacteraemic CAP-SP. A recent study by BADDOUR et al. [16] reported that in critically ill patients with bacteraemic pneumococcal illness, combination therapy was associated with a lower 14-day mortality (23.4 versus $55.3 \%, p=0.0015$ ), but this improvement in survival was independent on the class of antibiotics administered or the in vitro activity of the antibiotics prescribed. For noncritically ill patients, there was no difference in the 14-day mortality for patients treated with monotherapy versus combination. A number of possible explanations for the benefit of macrolides have been considered, such as antibiotic synergy, immunomodulatory effects and coverage of unrecognised atypical pathogens.

In spite of being the recommended regimen by a great number of guidelines for the management of CAP [27-29], theoretically, the combination of $\beta$-lactams + macrolides may be unwise, as the bacteriostatic agent may antagonise the effect of the bactericidal agent [15]. Some authors [30] have suggested that the combination of a macrolide and penicillin, if not synergistic, might at least not be antagonistic when the $\beta$-lactam agent is administered first, followed, some hours later, by the macrolide. Administration of multiple antimicrobials for CAP could also result in potentially more severe outcomes, in the form of increased drug-related adverse events. Onethird of the current patients were explored for the possible coexistence of atypical pathogens, but only Legionella spp. and C. pneumoniae were both found in three patients, which might explain why regimens covering these organisms did not substantially affect the outcome in the current study. Moreover, evidence is lacking that clinical outcomes are improved by using antibiotics that are active against atypical pathogens, at least in nonsevere CAP [31, 32].

It is reasonable to assume that inadequate therapy of infection leads to an excess of mortality. Furthermore, risk of exposure to DAT is directly related to the possibility of being infected with a resistant pathogen. Specifically, receipt of DAT as result of infection with a resistant $S$. pneumoniae strain has been reported to be associated with a significantly higher mortality [4]. However, the current authors have not found DAT to be related to mortality, and only the loss of susceptibility to penicillin in patients with renal failure has been found to be 
related. Current levels of penicillin resistance do not surpass MICs of $2 \mu \mathrm{g} \cdot \mathrm{mL}^{-1}$ [17], and serum and pulmonary levels achieved with $\beta$-lactams are several times higher than these. Even full penicillin resistance strains may be successfully treated if large enough doses of penicillin, in frequent enough dosing intervals, are given. Therefore, only a few patients with penicillin-resistant pneumococcal CAP receive a true DAT. In the current series, a significant number of DATs were found among patients receiving macrolide monotherapy. Considering the high level of resistance to macrolides in the current patients, this finding could have clinical significance. However, most of the patients receiving this DAT had a less severe pneumonia (PSI Class I-III) and the exact role that antimicrobials play in the outcome of these patients is probably less critical. Overall, combination therapy was used more commonly in the more severe cases (possibly expected to have a higher mortality) and macrolide monotherapy was used in the less severe patients.

It has been recently reported by MENENDEZ et al. [33], that guideline-compliant therapy was strongly associated with improved survival. It is obvious that patients in the current series with a PSI Class > III, who had received antimicrobials classified as other combinations, did not follow the recommendations stated in the local guidelines. However, not all patients' characteristics can be conveniently classified and it is possible that when a physician encounters a severely ill patient, they will choose an unusual regimen of antibiotics, knowing beforehand that the patient will have an elevated risk of mortality [34]. What the present study indicates is that in patients with PSI Class >III, as well as other factors, such as shock, bilateral pneumonia and HIV infection, the antimicrobial choice may also be independently related to mortality. Finally, mortality rates of bacteraemic pneumococcal disease vary greatly between centres [35], suggesting that factors others than antibiotic therapy may also be important in the current study.

The present work has several limitations common to any observational study in which empirical antimicrobial regimen have not been selected at random. Clinicians' decisions to prescribe combinations of antibiotics are based on factors relevant to the individual patient $[10,36]$ and, consequently, many factors in addition to antibiotic therapy could have accounted for the present results. In fact, as the current authors have stated, initial antimicrobial choice is related to baseline severity of illness. The route, dose and duration of antibiotic therapy, the potential role of antibiotics taken prior to hospital admission, timing of the initial dose, consistent supportive care among centres (e.g. criteria for ICU admission) and history of pneumococcal vaccination may be additional confounding factors that have not sufficiently been addressed in this study $[35,37-41]$. In contrast with other studies carried out in a very similar geographical area, but in just one hospital [13], which may contribute to the different findings observed, several recent prospective trials $[25,42]$ have not shown a benefit of combination therapy in CAP, although these trials were also flawed in some respects and again do not provide definitive answers. The present study adds to the controversy and in contrast to most large retrospective cohort studies, the patient population is well characterised, including severity of illness.
In conclusion, the current authors believe that the present evidence does not unequivocally support the use of any specific antibiotic agents or combinations in communityacquired pneumonia due to Streptococcus pneumoniae as long as this pathogen is rapidly and effectively covered. Randomised, prospective, blinded trials are needed to compare different antimicrobial regimens to demonstrate whether some of them offer true outcome advantages to community-acquired pneumonia patients.

\section{ACKNOWLEDGEMENTS}

The authors would like to thank F. Rodriguez-Salvanés and R. González-González of the Fundación de Investigación del Hospital de la Princesa (Madrid, Spain) for their invaluable assistance with the statistical analysis. Their contribution was extremely helpful and this manuscript would not have been possible without their generous effort.

\section{Pneumococcal Pneumonia in Spain Study Group}

Grupo TIR, Sociedad Española de Neumología y Cirugía Torácia, SEPAR.

Participating hospital (city, number of patients included per hospital), physician (type): Universitario Puerto Real (Cadiz, $\mathrm{n}=9$ ), A. Vargas (pulmonologist: PML), I. de la Calle (microbiologist: MCR); Virgen Macarena (Sevilla, $n=11$ ), J. M ${ }^{\mathrm{a}}$ Benítez (PML), M ${ }^{\mathrm{a}}$ J. Espinosa (MCR); Gral. Serranía de Ronda (Malaga, n=29), F. Cabello (PML), A. López (PML),

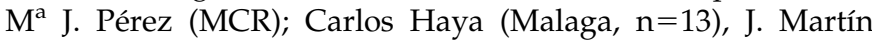
(PML), M. Arzola (PML), P. Manchado (MCR); Juan Ramón Jimenez (Huelva, $n=30), C$. Huertas (PML), J. M $M^{\text {a }}$ Saavedra (MCR), J. García (PML); Clínico universitario (Valencia, $n=39$ ), J. Blanquer (respiratory intensive care: ICU-PML), D. Pérez (PML), R. Borras (MCR); Universitario Doctor Peset (Valencia, $\mathrm{n}=6)$, R. Blanquer (PML), Á. Cervera (PML), J. Cervera (MCR); Francesc de Borja (Valencia, $n=7), M^{a}$ J. Cremades (PML), C. Navarro (PML), R. Igual (MCR); Marina Baixa (Alicante, $\mathrm{n}=20$ ), A. Martínez (PML), J. Calpe (PML), M. López (MCR); La fe (Valencia, $n=18), R$. Menéndez (PML), J. Vallés (PML), M. Gobernado (MCR); De Sagunto (Valencia, $n=16$ ), E. Martínez (PML), E. Fernández (PML), R. Escoms (MCR); Los Arcos (Murcia, n=7), $\mathrm{M}^{\mathrm{a}}$ J. Avilés (PML), M. Cámara (MCR); Universitario de la Princesa (Madrid, n=65), J. Aspa (PML), O. Rajas (PML), B. Buendía (MCR); Ntra Sra de Alarcos (Ciudad Real, $n=4)$, A. Mohamed (PML), F. Mora (MCR), D. Romero (MCR); Doce de Octubre (Madrid, $n=5$ ), C. Álvarez (PML), D. Folgueira (MCR), M. Lizasoaín (PML);

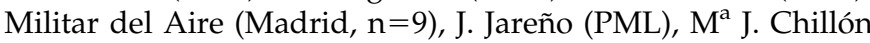
(PML), F. Villegas (PML); Fundación Jimenez Díaz (Madrid, $\mathrm{n}=10)$, R. Melchor (PML), J. García (PML), R. Fernández (MCR); Universitario de Guadalajara (Guadalajara, $n=2$ ), J. Gallardo (PML), J. Castelao (PML), T. Pérez (MCR); De Cruces (Vizcaya, n=49), R. Zalacain (PML), A. Gómez (PML), J. Hernández (MCR); San Millan-San Pedro (Logroño, n=7), M. Barrón (PML), M ${ }^{\mathrm{a}} \mathrm{J}$. Gastañares (MCR), $\mathrm{M}^{\mathrm{a}}$ J. Hermosa (PML); Cristal Piñor (Orense, $\mathrm{n}=25$ ), J. Tábara (PML), J. Lamela (PML), L. Barbeito (MCR); San Jorge (Huesca, $\mathrm{n}=27$ ), L. Borderías (PML), M. Ferrero (MCR); De Canarias (La Laguna, Tenerife, $\mathrm{n}=2$ ), R. Fernández (PML), J. Gullón (PML), Á. Torres (MCR); Central de Asturias (Asturias, $\mathrm{n}=9$ ), L. Molinos (PML), I. Folgueras (MCR); 
H. Universitario doctor negrin (Gran Canaria, $n=12$ ), F. Rodríguez de Castro (PML), I. Álamo (MCR); De Galdakao (Vizcaya, n=37), P.P. España (PML), I. Gorordo (PML), P. Berdonoes (MCR); Clinico (Barcelona, $n=26)$, R. de Celis (PML), F. Marco (MCR), A. Torres (PML); Comarcal de Igualada (Barcelona, $\mathrm{n}=6), \mathrm{M}^{\mathrm{a}} \mathrm{J}$. Cardona (PML), C. Sarrasela (MCR), J. Zapater (PML); C.h. Parc Tauli (Barcelona, $\mathrm{n}=37$ ), J. Rello (ICU-PML), M. Gallego (PML), M. Lujan (PML), D. Fontanals (MCR); Sant Joan (Tarragona, $n=23)$, S. Hernández (PML), R. Tomás (PML), F. Ballester (MCR); Municipal Badalona, (Barcelona, n=3), J. Oriol (PML), I. Carrasco (PML), A. Calderón (MCR); Santa Creu i Sant Pau (Barcelona, n=19), C. Puzo (PML), J. Tárrega (PML), F. Sánchez (MCR); Nostra sra de Meritxell (Andorra, $\mathrm{n}=14$ ), J. Roig (PML), J. Martínez (PML), X. Casal (MCR); Germans Trias i Pujol (Barcelona, $n=19)$, J. Ruiz (PML), F. Andreu (PML), J. Manterola (MCR); Dr. Josep Trueta (Girona, $\mathrm{n}=27), \mathrm{M}$. Vendrell (PML), A. Castro (internal medicine), J. Batlle (MCR).

\section{REFERENCES}

1 Pallares R, Linares J, Vadillo $\mathrm{M}$, et al. Resistance to penicillin and cephalosporin and mortality from severe pneumococcal pneumonia in Barcelona, Spain. $N$ Engl J Med 1995; 333: 474-480.

2 Ewig S, Ruiz M, Torres A, et al. Pneumonia acquired in the community through drug-resistant Streptococcus pneumoniae. Am J Respir Crit Care Med 1999; 159: 1835-1842.

3 Metlay JP, Hofmann J, Cetron MS, et al. Impact of penicillin susceptibility on medical outcomes for adult patients with bacteremic pneumococcal pneumonia. Clin Infect Dis 2000; 30: 520-528.

4 Lujan M, Gallego M, Fontanals D, Mariscal D, Rello J. Prospective observational study of bacteremic pneumococcal pneumonia: Effect of discordant therapy on mortality. Crit Care Med 2004; 32: 625-631.

$5 \mathrm{Yu}$ VL, Chiou CC, Feldman C, et al. An international prospective study of pneumococcal bacteremia: Correlation with in vitro resistance, antibiotics administered, and clinical outcome. Clin Infect Dis 2003; 37: 230-237.

6 Stahl JE, Barza M, DesJardin J, Martin R, Eckman MH. Effect of macrolides as part of initial empiric therapy on length of stay in patients hospitalized with communityacquired pneumonia. Arch Intern Med 1999; 159: 2576-2580.

7 Brown RB, Iannini P, Gross P, Kunkel M. Impact of initial antibiotic choice on clinical outcomes in communityacquired pneumonia: analysis of a hospital claims-made database. Chest 2003; 123: 1503-1511.

8 Gleason PP, Meehan TP, Fine JM, Galusha DH, Fine MJ. Associations between initial antimicrobial therapy and medical outcomes for hospitalized elderly patients with pneumonia. Arch Intern Med 1999; 159: 2562-2572.

9 Houck PM, MacLehose RF, Niederman MS, Lowery JK. Empiric antibiotic therapy and mortality among medicare pneumonia inpatients in 10 western states: 1993, 1995, and 1997. Chest 2001; 119: 1420-1426.

10 Rello J, Catalan M, Diaz E, Bodi M, Alvarez B. Associations between empirical antimicrobial therapy at the hospital and mortality in patients with severe community-acquired pneumonia. Intensive Care Med 2002; 28: 1030-1035.
11 Waterer GW, Somes GW, Wunderink RG. Monotherapy may be suboptimal for severe bacteremic pneumococcal pneumonia. Arch Intern Med 2001; 161: 1837-1842.

12 Mufson MA, Stanek RJ. Bacteremic pneumococcal pneumonia in one American City: a 20-year longitudinal study, 1978-1997. Am J Med 1999; 107: 34S-43S.

13 Martinez JA, Horcajada JP, Almela M, et al. Addition of a macrolide to a beta-lactam-based empirical antibiotic regimen is associated with lower in-hospital mortality for patients with bacteremic pneumococcal pneumonia. Clin Infect Dis 2003; 36: 389-395.

14 Burgess DS, Lewis JS 2nd. Effect of macrolides as part of initial empiric therapy on medical outcomes for hospitalized patients with community-acquired pneumonia. Clin Ther 2000; 22: 872-878.

15 Johansen HK, Jensen TG, Dessau RB, Lundgren B, Frimodt-Moller N. Antagonism between penicillin and erythromycin against Streptococcus pneumoniae in vitro and in vivo. J Antimicrob Chemother 2000; 46: 973-980.

16 Baddour LM, Yu VL, Klugman KP, et al. Combination antibiotic therapy lowers mortality among severely ill patients with pneumococcal bacteremia. Am J Respir Crit Care Med 2004; 170: 440-444.

17 Aspa J, Rajas O, Rodriguez de Castro F, et al. Drugresistant pneumococcal pneumonia: clinical relevance and related factors. Clin Infect Dis 2004; 38: 787-798.

18 Mortensen EM, Coley CM, Singer DE, et al. Causes of death for patients with community-acquired pneumonia: results from the pneumonia patient outcomes Research Team cohort study. Arch Intern Med 2002; 162: 1059-1064.

19 Fenoll A, Martin Bourgon C, Munoz R, Vicioso D, Casal J. Serotype distribution and antimicrobial resistance of Streptococcus pneumoniae isolates causing systemic infections in Spain, 1979-1989. Rev Infect Dis 1991; 13: 56-60.

20 Fenoll A, Jado I, Vicioso D, Perez A, Casal J. Evolution of Streptococcus pneumoniae serotypes and antibiotic resistance in Spain: update (1990 to 1996). J Clin Microbiol 1998; 36: 3447-3454.

21 National Committee for Clinical Laboratory Standards (2002) Performance Standards for Antimicrobial Susceptibility Testing: Twelfth Informational Supplement. Document M100-S12. Wayne, National Committee for Clinical Laboratory Standards, 2002.

22 Gilbert DN, Moellering RC, Sande MA. The Sanford Guide to Antimicrobial Vermont, Therapy. Antimicrobial Therapy, Inc, 2000.

23 Fine MJ, Auble TE, Yealy DM, et al. A prediction rule to identify low-risk patients with community-acquired pneumonia. N Engl J Med 1997; 336: 243-250.

24 Parmar M, Machin D. Survival Analysis. A practical Approach. New York, John Wiley and Sons, 1995.

25 Finch R, Schurmann D, Collins O, et al. Randomized controlled trial of sequential intravenous (i.v.) and oral moxifloxacin compared with sequential i.v. and oral coamoxiclav with or without clarithromycin in patients with community-acquired pneumonia requiring initial parenteral treatment. Antimicrob Agents Chemother 2002; 46: 1746-1754.

26 Menendez R, Torres A, Rodríguez de Castro F, et al. Reaching stability in community-acquired pneumonia: the 
effects of the severity of disease, treatment, and the characteristics of patients. Clin Infect Dis 2004; 39: 1783-1790.

27 Alfageme I, Aspa J, Bello S, et al. [Guidelines for the diagnosis and management of community-acquired pneumonia. Spanish Society of Pulmonology and Thoracic Surgery (SEPAR).]. Arch Bronconeumol 2005; 41: 272-289.

28 Niederman MS, Mandell LA, Anzueto A, et al. Guidelines for the management of adults with community-acquired pneumonia. Diagnosis, assessment of severity, antimicrobial therapy, and prevention. Am J Respir Crit Care Med 2001; 163: 1730-1754.

29 Mandell LA, Bartlett JG, Dowell SF, File TM Jr, Musher DM, Whitney C. Update of practice guidelines for the management of community-acquired pneumonia in immunocompetent adults. Clin Infect Dis 2003; 37: 1405-1433.

30 Ortega M, Marco F, Soriano A, Gómez J, Almela M, Mensa J. In vitro antagonism between $\beta$-lactam and macrolide in Streptococcus pneumoniae: how important is the antibiotic order? Int J Antimicrob Agents 2004; 24: 178-180.

31 Mills GD, Oehley MR, Arrol B. Effectiveness of beta lactam antibiotics compared with antibiotics active against atypical pathogens in non-severe community acquired pneumonia: meta-analysis. BMJ 2005; 330: 456-460.

32 Shefet D, Robenshtok E, Paul M, Leibovici L. Empirical atypical coverage for inpatients with community-acquired pneumonia: systematic review of randomized controlled trials. Arch Intern Med 2005; 165: 1992-2000.

33 Menendez R, Torres A, Zalacain R, et al. Guidelines for the treatment of community-acquired pneumonia: predictors of adherence and outcome. Am J Respir Crit Care Med 2005; 172: 757-762.
34 Aujesky D, Fine MJ. Does guideline adherence for empiric antibiotic therapy reduce mortality in community-acquired pneumonia? Am J Respir Crit Care Med 2005; 172: 655-656.

35 Kalin M, Ortqvist A, Almela M, et al. Prospective study of prognostic factors in community-acquired bacteremic pneumococcal disease in 5 countries. J Infect Dis 2000; 182: 840-847.

36 Dowell SF. The best treatment for pneumonia: new clues, but no definitive answers. Arch Intern Med 1999; 159: 2511-2512.

37 Macfarlane J. Severe pneumonia and a second antibiotic. Lancet 2002; 359: 1170-1172.

38 File TM Jr, Mandell LA. What is optimal antimicrobial therapy for bacteremic pneumococcal pneumonia? Clin Infect Dis 2003; 36: 396-398.

39 Waterer GW. Combination antibiotic therapy with macrolides in community-acquired pneumonia: more smoke but is there any fire? Chest 2003; 123: 1328-1329.

40 Meehan TP, Fine MJ, Krumholz HM, et al. Quality of care, process, and outcomes in elderly patients with pneumonia. JAMA 1997; 278: 2080-2084.

41 Powers JH, Cooper CK. Evaluating combination therapy in community-acquired pneumonia. Chest 2004; 125: 353.

42 File TM Jr, Segreti J, Dunbar L, et al. A multicenter, randomized study comparing the efficacy and safety of intravenous and/or oral levofloxacin versus ceftriaxone and/or cefuroxime axetil in treatment of adults with community-acquired pneumonia. Antimicrob Agents Chemother 1997; 41: 1965-1972. 